\title{
The Enterprise Risk Management and the Risk Oriented Internal Audit
}

\section{Jie Liu}

School of Accounting, Shandong Institute of Trade Unions' Administration Cadres, Jinan, China. Email: Old-bu@163.com

Received May $18^{\text {th }}, 2012$; revised June $18^{\text {th }}, 2012$; accepted July $18^{\text {th }}, 2012$

\begin{abstract}
With the development of the economic globalization, the risks that enterprises faced are increasing. In order to cope with the risks, the enterprise risk management requires the internal audit. As an important part of the internal control, the risk oriented internal audit emerges to monitor the process of the enterprise risk management. So enterprises can control and evaluate the risks more and more suitable. The research focused on the importance of the risk oriented internal audit, and also studied the status of our risk oriented audit, then the research proposed some strategies and suggestions to promote the application of the risk oriented internal audit so as to ensure the effectiveness of the enterprise risk management.
\end{abstract}

Keywords: Risk Management; Internal Audit; Risk Oriented

\section{Introduction}

The 21 st century is a century that can bring challenges and chances to enterprises. The economical globalization, the information technology revolution and the brand-new form of enterprise, have caused the risks which the enterprise faces complex and intense day by day. The risks have been the most important factor that influences the goal of enterprise to realize. Therefore, how to manage the risks and avoid them is the most important thing to the management of the enterprises now. The management of the enterprises has to analyze and avoid risks from the entire enterprise's angle. Modern risk management is a process that participated by everyone of the enterprise, applies in the enterprise strategy plan and every interior departments, distinguish the potential risk and manage them in their tolerable risk scope, so as to assure the goal of the business to be realized. The managerial staff control the risks and reduce loses, enhance the profit and social effect of the enterprise through the enterprise risk management. The development of the enterprise needs the risk management, yet the development of the risk management needs the support of the internal audit. Gerrit Sarens, et al. [1] and George Bartsiotas [2] pointed out that the internal auditors should put forward suggestions and help the managerial staff fulfill its responsibility through monitoring the adequacy and the effectiveness of the risk management.

Therefore, the risk oriented internal audit is not only the result of the changes of the environment and the de- velopment of the enterprises, but also the development of the internal audit and the development of the exterior audit. Liu Jie [3] pointed out that the risk oriented internal audit is an independent, objective guarantee and consulting activity that oriented by risk. It sets up the precedence of the audit project according to the quantification analysis level; sets up the audit scope and the key points of the audit according to the basis risk determination; appraise the process of the risk management, the internal control and the corporate governance so as to propose the constructive suggestion to realize the value increment of the enterprise. Its objects, aims, audit ranges, audit technologies, audit routes and functions are all changed enormously. Through examine the risk management, the internal auditors can find out the risks, estimate the risk management and give advices to improve it, and help to add values to the enterprises. The function of the risk oriented internal audit in the enterprise risk management including evaluate the sufficiency of risk recognition, evaluate the appropriateness of the risk assessment, evaluate the properness of the risk-avoid measure, understand the acceptable risk level of management, and report the risk management appraisal situation to the management regularly. In a word, the duty of the risk oriented internal audit in the risk management including: 1) Assisting the management of the enterprises in establishing the risk management system; 2) Appraising the sufficiency and effectiveness of the risk management; 3) Assisting the management of the enterprises in determineing, appraising and implementing the risk management 
methods and the control measures.

The foreign internal audit has entered into the risk guidance stage, and their fundamental researches have been mature. The English Internal Audit Association promulgated "Position Statement: The Role of Internal Audit in Enterprise-Wide Risk Management", the International Internal Auditor Association promulgated "Internal Audit Practice Standard", McNamee D. and G. Selim put forward the risk oriented internal audit model, which provided the theory instruction for the risk oriented internal audit. The foreign internal audit has plentiful audit types, their audit methods are advanced, and their relationships with others are harmonious. However, the risk oriented internal audit in our country is still at the prime stage. Through the investigation, we discovered that the internal audit in our country has such problems as the imperfect risk management system in the enterprise, the under-developed risk management method used in the enterprise, the internal audit can not play its role perfectly and the single internal audit personnel structure, etc. In view of the above questions, this article proposed some strategies and suggestions of the risk oriented internal audit to promote the development of our risk oriented internal audit.

\section{The Relationship of the Risk Oriented Internal Audit}

\subsection{Risk Management Requires the Internal Audit}

Yang Rui and Diao Min [4] pointed out that just because the risk oriented internal audit can help other departments of the enterprise to control the risks through effective consulting and evaluating activities. The enterprise risk management requires the internal audit to monitor, control, inspect, evaluate, and report the proceeding of the enterprise risk management. As the risks that enterprises may faced are comprehensive, a sort of risks which caused by one department may be transferred to other departments, even lead the whole enterprise into trouble, so understanding the risks, precaution and control the risks must under overall consideration. Just as each department has its own limitations to realize the risks from the entire situation, so that the internal audit is important enough to resolve these problems, for example, the internal auditors can distinguish different sorts of risks from the economic activities and give applicable suggestions in time.

Many organizers of the enterprises have realized that the effectiveness of the enterprise risk management and the appropriateness risk management strategy is closely related to the goal of the enterprises. The risk oriented internal audit targets the enterprise risk management as the main point of the audit, it inspects, evaluates all sorts of the risks they may face in the continuance operate of the enterprise, and appraises whether the enterprise risk management is effective and efficient, whether the strategy of the enterprise risk management is appropriate to the development of the enterprise. The risk oriented internal audit can meet the need of the enterprise risk management, and can help the enterprise risk management system be more and more suitable at the same time.

\subsection{Internal Audit Requires the Risk Management}

The risk oriented internal audit is the internal control expanding to the enterprise risk management, which has important influence on the traditional internal audit. Traditional internal audit puts emphasis on direct testing of the internal control, appraising and considering, whether the internal control is sound and effective or not. It tries to find out the weak links of the internal control in order to achieve the goal of preventing mistakes and frauds. Just because it suggests that some weak links should increase control points, so that more and more control points lead the business process to slow and no efficiency. Therefore, the traditional internal audit gradually reduced to increasing the business value.

While the risk oriented internal audit pays attention to the possibility of all sorts of the risks that maybe face in the process of the corporate governance, it puts the audit key forward to the present and future program. It selects audit projects by using the risk criteria and each audit objective is closely related to the goals of the enterprise. The risk oriented internal audit begins with risks and ends at risks, and risks connect with the audit process closely from the beginning to the end. It provides more relevant information to the management which is needed to achieve its goal.

\subsection{The Risk Oriented Internal Audit Integrated the Corporate Governance, the Enterprise Risk Management and the Internal Control}

The traditional internal audit limited to the internal control, it has not paid much attention to the corporate governance and the enterprise risk management. However, the corporate governance requires the internal control to provide protection, and the enterprise risk management also requires the internal control to realize the effective risk management through a variety of methods. Therefore, the internal audit should integrate the corporate governance, the enterprise risk management and the internal control, so as to strengthen the management, improve the efficiency and establish a good operation order.

\section{The Status of Our Risk Oriented Audit}

The risk oriented internal audit not only pays attention to 
the enterprise risk management, but also becomes one of the important parts of the enterprise risk management. Just because the significance status of the risk oriented internal audit, many states issued various policies to extend it. For example, in September 2004, COSO formally issued "Enterprise Risk Management Framework", whose outstanding theoretical value and practical significance makes it arouse widespread concern.

However, the application situation of our risk oriented internal audit is not optimistic.

To understand our risk oriented internal audit application status, this article adopts questionnaire and interview method, release 200 questionnaires in June, 2010 to January, 2011. The questionnaire is formed on interviews and literature analysis. The initial questionnaire is based on the interview to 14 enterprises which carried out the risk oriented internal audit, through the depth interviews and the investigation, we found out the common problems and the difficulties existed in the development of our risk oriented internal audit, and according to the findings to revise the questionnaire again. We selected 200 enterprises which want to carry out the risk oriented internal audit to do the investigation and retrieve 178 samples, in which the effective samples are 137. Through the questionnaire survey, we discovered some ubiquitous questions, and provided the corresponding suggestions. The questionnaire and the survey results are as shown in Table 1.

\subsection{Our Risk Oriented Internal Audit Is Still in the Initial Stage}

Our circles of theory and practice have realized the importance of the risk oriented internal audit and begin to study it already, but our internal auditors still mainly concern on the financial revenues, economic benefits and economic responsibilities. Some of the internal audits do not play any role in the enterprise risk management,

Table 1. The status of our risk oriented audit questionnaire.

\begin{tabular}{lcc}
\hline \multicolumn{1}{c}{ Questions } & Results \\
\hline $\begin{array}{l}\text { 1) The position of our internal audit organization } \\
\text { a) An independent organization }\end{array}$ & 43 & $62.32 \%$ \\
b) Combined with other departments & 23 & $32.59 \%$ \\
c) Have not established a special internal audit & 3 & $4.35 \%$ \\
organization & \\
2) The education situation of our internal audit organization & \\
a) Master & 2 & $0.37 \%$ \\
b) Bachelor & 499 & $91.90 \%$ \\
c) College degree & 39 & $7.18 \%$ \\
d) Under the College degree & 3 & $0.55 \%$ \\
\hline
\end{tabular}

\section{Continued}

3) The professional situation of our internal audit organization

$\begin{array}{lcc}\text { a) Audit } & 152 & 27.99 \% \\ \text { b) Accounting } & 265 & 48.43 \% \\ \text { c) Management } & 55 & 10.13 \% \\ \text { d) Computer } & 4 & 0.74 \% \\ \text { e) Engineering } & 54 & 9.94 \% \\ \text { f) Others } & 13 & 2.39 \%\end{array}$

4) What kinds of audit project is the internal audit carried out?
a) Financial revenues audit
$48 \quad 69.57 \%$
b) Economic benefits audit
$46 \quad 66.67 \%$
c) Economic responsibilities audit
$50 \quad 72.46 \%$
d) Capital construction audit
$35 \quad 50.72 \%$
e) Law and order special audit
$16 \quad 17.42 \%$
f) Assessment of internal control
$33 \quad 47.83 \%$
g) Audit investigation
$30 \quad 43.48 \%$
h) Risk oriented internal audit
$14 \quad 17.39 \%$

5) Who are responsible for the risk management?
a) The board of the enterprise
$12 \quad 19.67 \%$
b) The board of supervisors
$0 \quad 0$
c) The Audit Committee
$4 \quad 6.56 \%$
d) The president
$32 \quad 39.02 \%$
e) The vice president
$6 \quad 9.84 \%$
f) The internal audit
$15 \quad 24.59 \%$
g) Others
$13 \quad 21.31 \%$

6) How did the enterprise control and evaluate the risks faced by the enterprise?
a) The requirements of laws and regulations
37
$60.66 \%$
b) There are a specialized group to identify the risks
$7 \quad 11.48 \%$
c) Identify the risks by qualitative methods $\quad 13 \quad 21.31 \%$
d) Identify the risks by quantitative methods $\quad 4 \quad 6.55 \%$

7) What role is the internal audit played in the enterprise risk management?

\begin{tabular}{lcc}
$\begin{array}{l}\text { a) Participated in the process of the enterprise } \\
\text { risk management }\end{array}$ & 53 & $64.39 \%$ \\
$\begin{array}{l}\text { b) Set up the risk preferences and risk } \\
\text { tolerance }\end{array}$ & 7 & $8.54 \%$ \\
$\begin{array}{l}\text { c) Monitor the process of the enterprise risk } \\
\text { management }\end{array}$ & 7 & $8.54 \%$ \\
$\begin{array}{l}\text { d) Training the enterprise risk management } \\
\text { personnel }\end{array}$ & 17 & $20.73 \%$ \\
$\begin{array}{l}\text { e) Did not participate in } \\
\text { f) Others }\end{array}$ & 15 & $18.29 \%$ \\
& 5 & $6.10 \%$ \\
\hline & &
\end{tabular}


partly of them can remind the management to pay attention to the risk, a few of them provide personnel training to the enterprise risk management. How to apply the internal audit to the enterprise risk management still needs to be researched.

\subsection{Our Enterprise Risk Management Is Not Perfect}

According to the survey, there are $80.49 \%$ of the enterprises have not set up a special risk management organization, $39.02 \%$ of the enterprises carried out the risk management activities by the president, $21.31 \%$ of the enterprises did not have formal risk management activities, $60.66 \%$ of the enterprises purchase mandatory insurance according to the law, rarely according to their own consideration. The survey shows that we have not established a perfect risk management system yet, the enterprise risk management activities are in accordance with the laws and requirements of passive, which does not in accordance with the requirements of enterprises' own account. Therefore, this kind of behavior is instantaneous and intermittent, and usually carried out after the events, which obviously can not meet the needs of the enterprise to deal with the fierce market competition and the requirements of the development in the multiple risk environment.

\subsection{Our Enterprise Risk Management Measures Are Under-Developed}

Li Xiaochun, et al. [5] pointed out that just a few of the enterprises are using the quantitative analysis method to carry out the enterprise risk management. Most of the enterprises are still adopting qualitative analysis method, compared with the mathematical statistical model, financial engineering and other advanced measures are widely used by the advanced international enterprises, our enterprise risk management measures are relatively underdeveloped. The backward measures of our enterprise risk management due to lack of the instruction of mature theory, while the backward measures of our enterprise risk management directly cause the enterprises can not appropriate to predict risks, identify risks, assess risks and respond to risks, thus will affect the enterprises to realize its goal.

\subsection{The Internal Audit Personnel Structure Is Single}

From the investigation, most of our internal auditors have the higher education, there are $99.45 \%$ of the internal auditors have the education in college or above. However, the internal audit personnel structure is too single, nearly half of the internal auditors graduated from accounting major, nearly $1 / 4$ of the internal auditors graduated from audit major, less than $1 / 4$ of the internal auditors graduated from the management, computer, engineering or other related major. Single structure of the internal auditors affects the internal audit and leads to the narrow audit scope, low efficiency, and difficult to give comprehensive evaluation to the enterprise risk management and the corporate governance.

\subsection{Our Internal Audit Organization Lack of Independence}

Our internal audit organization is established by the government's intervention and promotion, which lacks of relative independence and suitable standard. As the operating expenses and personnel salaries all depend on the enterprise management, when the management does something illegal or unreasonable, the internal auditors are full of worries to perform the functions of supervision and evaluation.

In addition, the different risks faced by the enterprise need the internal audit blend with the enterprise risk management and participate in the strategic planning positively, yet our internal audit organization always accept instructions from the management passively, so when the internal auditors making the audit plan, carrying out audit procedures and issuing the audit report, there are all kinds of prevention to carry out independent audit activities.

\section{Strategies and Suggestions}

\subsection{Mobilize the Enthusiasm of the Internal Audit Blend with the Enterprise Risk Management}

We should change our internal auditors' ideas as soon as possible, it will backward if the modern internal audit does not pay attention to the enterprise risk management. The western enterprises have modified the internal audit charter, and require the internal audit to participate in the enterprise risk management, provide independent evaluation and recommendations. Our internal audit also need to update their concepts, switch their roles, and strengthen communication with every department of the enterprise, mobilize the enthusiasm of internal audit blend with the enterprise risk management.

\subsection{Accelerate the Construction of Laws and Regulations}

A suitable law system will promote the development of a new method, if the relevant departments can accelerate the laws and regulations to be issued, and emphasize the importance of carrying out the risk oriented internal audit, the effect will be more obvious. 


\subsection{Make Full Use of the Audit Conclusion}

Internal auditors should verify the target of the enterprise together with the departments be audited, and should inform them all of the discoveries found out from the audit process. The departments should assist in the audit work more efficiently by using their professional skills and insights, as for the difficulties among the audit process, which should be resolved by consultations. The departments be audited should participate in the fully discussion on the audit reports with the internal auditors, so as to ensure the problems found out by the internal auditors can be discussed thoroughly, and the audit conclusion can be used thoroughly.

\subsection{Establish a Learning Organization of the Internal Audit, and Improve the Internal Auditors' Quality}

Yang Huixian and Fu Rong [6] pointed out that the quality of internal auditors determines whether the risk oriented internal audit can be carried out effectively, and whether the efficiency of the internal audit can be improved effectively. So the risk oriented internal audit asked for higher requirements than traditional internal audit. The risk oriented internal auditors should not only master the audit knowledge, but also have the economic management knowledge, the finance knowledge, the statistics knowledge, the engineering knowledge, the law knowledge, the information and computer expertise, and should be good at the enterprise risk management knowledge, they can be more proficient in using scientific method to measure the risks, assess the risks and control the risks. They can help the enterprises to establish a perfect risk management system, which includes the enterprise management strategies and methods. Establish a learning organization of internal audit, and improve the internal auditors' quality is not only based on the objective requirements of the risk oriented internal audit, but also based on the objective needs of the internal audit's survival and development.

Therefore, we should establish strict internal auditor's selection system, recruitment system, training system and performance evaluation system, in order to ensure the quality of the internal auditors and the diversification of the internal audit personnel structure. For example, we can select the staff who are familiar with the enterprise's production and operation activities to enrich the internal audit organization, or recruit experienced professionals from colleges and universities or from the accounting firms or other industries. We should pay attention to the continuing education and the occupation morality construction of the internal auditors, strengthen the personnel's consciousness of responsibility, promote the strict principles, diligent principles and the enterprising spirit of the occupation.

\subsection{Improving Communication Skills, Modifying the Interpersonal Relationship}

Most of our internal audit organizations are established by the external forces, as the need of the government or relevant regulations, the departments audited are always in strong feelings with the internal auditors, which are obviously not conducive to the audit work.

However, in the environment where most of the internal auditors have the same intelligence quotient level, whether the work can proceed smoothly or not mostly depends on the emotional quotient level, which is mostly depends on the interpersonal skills and communication ability. The particular duty of the internal auditors decides that they must improve their communication skills, self-control ability, innovation ability, comprehension ability and cooperation ability. All of that are helpful to improve the ability of their emotional intelligence, modify their interpersonal relationship, which will help them to change the attitude of the other departments to the internal auditors, and help them to understand the role, the responsibilities and the work procedures of the internal audit, which will change the passive resistance to actively cooperate with the internal audit.

\section{Conclusion}

In a word, the risk-oriented internal audit is not only the result of the changes of the environment and the development of the enterprise, but also the development of the internal audit and the development of the enterprise risk management. We should follow the suggestions improved above to promote the development of the riskoriented internal audit, so that the risk management can play a better role.

\section{REFERENCES}

[1] G. Sarens, I. De Beelde and P. Everaert, "Internal Audit: A Comfort Provider to the Audit Committee," The British Accounting Review, Vol. 41, No. 2, 2009, pp. 90-106. doi:10.1016/j.bar.2009.02.002

[2] G. Bartsiotas, "An Expanding Role," Internal Auditor, Vol. 2, No. 4, 2008, pp. 86-91.

[3] J. Liu, "The New Pattern of Internal Audit-Risk Oriented Internal Audit," Finance and Accounting Monthly, Vol. 3, No. 8, 2006, pp. 77-79.

[4] R. Yang and M. Diao, "The Enterprise Risk Management and the Risk Oriented Internal Audit," Finance and Accounting Monthly, Vol. 12, No. 36, 2008, pp. 52-54.

[5] X. C. Li, W. H. Gao and Y. P. Li, "The Research on the Application of the Risk Oriented Internal Audit in Our Country," Accounting Communications, Vol. 4, No. 12, 
2011, pp. 98-100.

[6] H. X. Yang and R. Fu, "The Research on the Risk Ori- ented Internal Audit Literature Review," Accounting Communications, Vol. 7, No. 21, 2009, pp. 73-89. 